University of Wollongong

Research Online

2014

Supporting service change in palliative care: a framework approach

Jennifer Tieman

CareSearch

Deborah Rawlings

CareSearch

Janet Taylor

Palliative Care Outcomes Collaboration, janet.taylor@flinders.edu.au

Amanda Adams

Flinders University

Shyla Mills

Palliative Care Australia

See next page for additional authors

Follow this and additional works at: https://ro.uow.edu.au/ahsri

Research Online is the open access institutional repository for the University of Wollongong. For further information contact the UOW Library: research-pubs@uow.edu.au 


\title{
Supporting service change in palliative care: a framework approach
}

\begin{abstract}
Background: Palliative care services are increasingly identifying areas for improvement, then trying to create appropriate changes in response. Nurses in particular are often expected to take leading roles in quality improvement (QI) but are not necessarily trained or supported in these processes. Methods: A framework approach to change was developed to guide services through a change cycle and delivered via workshops by representatives of three Australian national projects. Participants were predominantly nurses (80\%), with the majority (63.7\%) over the age of 50. Findings: The workshops and the framework were positively evaluated, with participants feeling confident in a number of QI-related activities following workshop training. Conclusion: Recognising and addressing problems in clinical practice and service delivery is an important way for nurses to ensure quality care for patients; however, they need support in developing the skills and knowledge that are essential to successful QI activities.
\end{abstract}

\section{Keywords}

approach, service, framework, supporting, care, palliative, change

\section{Publication Details}

J. Tieman, D. Rawlings, J. Taylor, A. Adams, S. Mills, H. Vaz \& M. Banfield, "Supporting service change in palliative care: a framework approach", International Journal of Palliative Nursing 207 (2014) 349-356.

\section{Authors}

Jennifer Tieman, Deborah Rawlings, Janet Taylor, Amanda Adams, Shyla Mills, Helen Vaz, and Maree Banfield 


\section{Supporting service change in palliative care: A framework approach}

\section{Jennifer Tieman}

CareSearch Director and Associate Professor, Palliative and Supportive Services, Flinders University, GPO Box 2100 Adelaide, South Australia 5001, Australia

\section{Deb Rawlings}

CareSearch Research Officer, Palliative and Supportive Services, Flinders University, GPO Box 2100 Adelaide, South Australia 5001, Australia

Ph: +61872218215

Fax: +61872218238

E: deborah.rawlings@flinders.edu.au

\section{Janet Taylor}

Quality Improvement Facilitator (SA \& NT) Palliative Care Outcomes Collaboration, Palliative and Supportive Services, Flinders University, GPO Box 2100 Adelaide, South Australia 5001, Australia

\section{Amanda Adams}

CareSearch Research Assistant, Palliative and Supportive Services, Flinders University, GPO Box 2100 Adelaide, South Australia 5001, Australia

\section{Shyla Mills}

Manager, National Standards Assessment Program, Palliative Care Australia Inc, PO Box 24, Deakin West, Australian Capital Territory 2600, Australia

\section{Helen Vaz}


Quality Manager, National Standards Assessment Program, Palliative Care Australia Inc, PO Box 24, Deakin West, Australian Capital Territory 2600, Australia

\section{Maree Banfield}

Quality Manager, Palliative Care Outcomes Collaboration, Australian Health Services

Research Institute, iC Enterprise 1 Innovation Campus University of Wollongong New South Wales 2522, Australia 


\begin{abstract}
Background

Palliative care services are increasingly identifying areas for improvement, then trying to create appropriate changes in response. Nurses in particular are often expected to take leading roles in Quality Improvement (QI) but are not necessarily trained or supported in these processes.
\end{abstract}

\title{
Methods
}

A framework approach to change was developed to guide services through a change cycle, and delivered via workshops by representatives of three Australian national projects. Participants were predominantly nurses (80\%) with the majority $(63.7 \%)$ over the age of 50 . The workshops and the framework were positively evaluated with participants feeling confident in a number of QI related activities following workshop training.

\section{Conclusion}

Recognising and addressing problems in clinical practice and service delivery is an important way for nurses to ensure quality care for patients; however, they need support in developing the skills and knowledge that are essential to successful QI activities.

\section{Keywords}

Palliative care, quality improvement, change implementation, change framework 


\section{Introduction}

As demands upon health services and systems grow, more focus is being directed to how services can improve their care practices and outcomes and utilise their resources most effectively (Wong et al 2012, Macdonald et al 2013, Gordon et al 2014). Health care services are increasingly being provided with, or are initiating activities which will result in, data and findings that highlight areas of need or areas for improvement within their organisation. Feedback from audits, complaints, self-reflection and annual reviews, as well as participation in more formal processes such as standards review and assessment, benchmarking and quality improvement (QI) cycles, can highlight issues and areas for attention. However, difficulties can arise as the service considers how to address the need for change, with competing work priorities and issues such as time, staffing and lack of knowledge or confidence in change management processes all potentially having an impact on the ability to proceed (Kerridge, 2012). Furthermore, services often function in isolation, and therefore work independently in trying to effect changes at the local level.

Despite these barriers, services are frequently expected to be involved in continuous quality improvement with nurses often expected to take leading roles in QI, or to be involved in change management processes. However, it is only fairly recently that quality improvement science has been introduced into undergraduate and postgraduate nursing curricula (Jones et al 2013, Smith et al 2013) and into continuing education (van Hoof and Meehan, 2013). Hence, many nurses may have only a limited knowledge of QI or change management theory and methods.

These issues also affect palliative care service provision and care delivery, with increasing interest in enhancing patient outcomes, supporting equity and access to palliative care and maximising the contribution of palliative care services to the health care sector (Dale et al 2009, Kamal et al 2011, Woo et al 2011, McMillan et al 2011, Lau et al 2013). The Agency for Healthcare Research and Quality's review report, "Closing the Quality Gap: Revisiting the 
State of the Science", noted that, despite high - quality evidence in several areas, substantial gaps in care delivery remain (Dy et al, 2012). This review indicated that pain remains undertreated despite effective therapies, and highlighted that many patients remain unaware of their prognosis, are uncertain of the risk and harms associated with treatment options, and along with their carers continue to experience unmet needs (Dy et al, 2012).

In Australia, Commonwealth Government funding has supported a number of national palliative care projects designed to improve the quality of care being provided. Three of these national projects formalised a relationship through a memorandum of understanding which recognised their shared interest in improving palliative care by increasing the skills of palliative care services, facilitating quality improvement, and encouraging the use of evidence in practice. The three participating projects were:

- CareSearch (Flinders University): An online resource providing health professionals and patients, carers and families with access to palliative care information, resources and evidence. It provides access to evidence on clinical and service issues as well as QI and change management.

- National Standards Assessment Program (NSAP) (Palliative Care Australia): A national QI approach that enables services to engage in a structured process of selfassessment against Palliative Care Australia's Standards for Providing Quality Palliative Care for All Australians (Palliative Care Australia, 2005). Services complete a self-assessment snapshot every 2 years against the standards and create and implement a QI action plan, based on these results.

- Palliative Care Outcomes Collaboration (PCOC) (University of Wollongong): A voluntary quality program utilising standardised validated clinical assessment tools to measure patient outcomes and then benchmark these outcomes with similar services' outcomes in palliative care. Participation in PCOC helps services to identify 
outcomes for improvement via a benchmarking report every 6 months and an annual benchmarking workshop.

Despite the support offered by the three projects, services reported that they faced problems in trying to determine which needs to address, what changes to make, and how to make changes that maximised the return for their efforts and had positive outcomes for staff, the health service, patients and families.

The aim of this project was to develop an aligned framework approach to change and to evaluate whether it would provide practical support to those involved in QI activities in palliative care.

\section{Methods}

A working group with representatives from the three projects was established in March 2011 to identify common issues around change implementation being experienced by services and clinicians involved with the individual projects. A rapid literature review on QI, implementation processes and evidence - based change was undertaken August 2011. From the literature, it was evident that there is an increasing interest in the relationship between evidence - based practice and QI and in how evidence can inform choices made and processes used in QI activities was evident (Glasziou et al 2011, Bosch et al 2012, Haley et al 2012). Research evidence can inform what can be included in the proposed QI activities as well as the best methods and strategies to direct change and outcomes. Glasziou et al (2011) also highlighted the possibilities afforded by QI in enabling a mechanism for translating evidence for use in local contexts. Collaborations and data collection systems also provide an opportunity to support improvement and research (Clancy et al, 2013). Researchers and trainers have highlighted the importance of those involved in QI processes establishing functional goals, developing action plans, implementing specific and measurable actions and monitoring progress when undertaking change activities 
(Hughes 2008, Cole 2009, Ovretveit and Klazinga 2012). The importance of education and training has also been recognised (Daugherty et al, 2013). There is an understanding that the evidence base for QI science is still evolving and that there are still large gaps in a knowledge base to guide individual and system quality initiatives (McDonald et al, 2013).

The working group reviewed the findings from the literature overview in September 2011 and the group discussions were informed by issues documented in the individual project reports and studies (NSAP National Quality reports, PCOC reports) and studies (Tieman and Rawlings 2008). At this meeting, the planning group agreed to develop an aligned approach to facilitate change management, and the 'Working Together Change Framework' (WTCF) was developed, comprising six questions to guide planning and conduct of QI activities (Figure 1).

This procedure for QI activity and / or change owed much to the approach suggested by van Bokenhoven et al (2003) but was contextualised to the specific needs of the palliative care sector as experienced through the three projects. To introduce this framework to palliative care services, and evaluate its impact, a series of workshops were planned for delivery in 2012. The workshops were designed to support attendees to identify a problem, analyse the cause, source evidence and measures, create an implementation plan and review what happens. Ethics approval for the evaluation was received through Flinders University (No. 5707).

\section{Workshop recruitment}

Attendance at workshops was voluntary and self-selected. As there was no direct funding for this project, to encourage attendance the WTCF workshops were scheduled to be held immediately before a half-day NSAP update meeting that did fund travel and accommodation costs for meeting attendance. Both the WTCF workshops and the NSAP update meeting were held adjacent to conferences relevant to palliative care, again to 
encourage attendance. Five workshops were conducted - in Adelaide (South Australia), Melbourne (Victoria), Launceston (Tasmania), Perth (Western Australia) and Dubbo (New South Wales). Invitations to the WTCF workshops and the NSAP update meeting were sent by NSAP to all specialist palliative care services in each State and Territory. The WTCF workshops were also advertised on the CareSearch, PCOC and NSAP websites, and through stakeholders. Participation in the workshop was not dependent on the individual's being willing to participate in the workshop evaluation. Completion of the evaluation form was considered to be provision of consent to participate in the evaluation, as indicated in the ethics approval..

\section{Workshop format}

The workshops were facilitated by staff from each of the three projects, who modelled collaborative working relationships and the connection between evidence, standards and outcomes. Each workshop started with an introduction to the evaluation, clarifying what was involved in participation. A presentation on the WTCF followed. Services were provided with information on a mock palliative care service, which drew on hypothetical PCOC and NSAP reports. CareSearch staff provided an overview of the importance of evidence in the change process and specific evidence sources relevant to the identified change issues. The workshops focused on one of two topics: pain and carer support. These had been identified as high - priority issues by both the NSAP and PCOC projects and were also reported in the literature of issues of importance in palliative care. Following the didactic presentations, each group was also provided with templates for problem analysis, details on the six questions sequence and sources of evidence, relevant to the topic. Participants then planned a QI approach with measures of change for the mock service before reviewing the proposed approaches as a group.

To prompt interest and to encourage QI action, all workshop participants who provided an email address were sent email updates with further information relevant to the carer or pain 
themes at 3 weeks and 6 weeks post workshop. It was a concern that, once back in practice, with work pressures, the knowledge from the workshop could be lost. It was thought that if further information was supplied, attendees might be encouraged to talk to colleagues about the WTCF and possibly look at areas to focus on. The workshop format and materials can be found on the CareSearch website: (www.caresearch.com.au/caresearch/tabid/3003/Default.aspx)

\section{Workshop Evaluation and Follow up Study}

Workshop participants were invited to complete an evaluation immediately after the workshop. Those who completed the post - workshop evaluation were eligible to participate in a follow up evaluation. These participants were sent a further survey at 8 weeks that asked whether they had commenced any QI activity and whether the workshop information had been used in practice.

\section{Data Analysis}

Reponses to the survey were received and managed by a research assistant, and were entered and analysed using SPSS (IBM), with none of the researchers aware of who had participated in the study. Content analysis of responses to the open questions in the surveys involved the extraction of the comments by question field to create a Comments Dataset. Emergent coding of the comments by one of the investigators [JT] resulted in the development of categories applied to all comments. The question field was treated as the unit of analysis. Therefore, each question field could have several codes applied (Graneheim and Lundman, 2004).

\section{Results}

\section{Participation}

A total of 81 people participated in one of five workshops. Fifty six participants completed a workshop evaluation. Of these, $13(23 \%)$ completed a follow up survey at 8 weeks. Twenty 
five workshop participants did not complete a workshop evaluation and hence received only the emails to prompt for future action and to provide further QI and content information.

The demographics of the participants were collected, with the majority holding nursing roles within their organisation, with $45(80 \%)$ held nursing roles in their organisation (three participants did not provide their role) (Table 1). Fifty five participants provided their age (Table 2).

\section{Workshop Evaluation}

The responses from the workshop evaluation forms are summarised in Table 3. The data show that $23.2 \%(13 / 56)$ were extremely satisfied with the workshop overall and a further $53.6 \%(30 / 56)$ were satisfied. Eighty nine percent agreed or strongly agreed that the content was relevant to their needs. Between $69.8 \%$ and $81.8 \%$ felt more confident in a number of QI related activities following participation in the workshop (Table 3).

Many of the free text comments made by participants demonstrated positive sentiments. I love the key message of "shrinking the thinking" in relation to thinking about breaking down the problem conceptually to smaller units/specifics. PW4013

Change management is difficult however this workshop provided basic tools to assist me. PW4006

Thirty nine responses were provided to the free text question "What was the most useful thing you learnt today?" and several themes emerged. The first related to the value of a structured approach to support QI activities.

Having the framework circle [WTCF] to work through to formalise the process AW 1006 
The 6 questions [WTCF] and how to apply them in practice LW3016

Systematic approaches reinforced and write down each step down/document your planning. PW4007

The second theme was around three services/projects working together.

Using NSAP, PCOC and CareSearch data to build a plan AW1013

Seeing the representatives of the three organisations together on the same podium DW5005

The third theme related to the value of the data already being captured and the evidence resources available.

Variabilities and aspects of service outcomes which can be extracted from PCOC and NSAP data DW 5010

How national and state data can be used on the ground MW2013

Twenty seven comments were received in relation to improving the content and format. These related to logistical or organisational suggestions (10) requests for rural specific content (7), requests for project specific information (4) and advertising (2). Twenty three comments were received in response to the question on how to encourage the application of evidence to QI activities among palliative care professionals. These included practical suggestions (9), comments relating directly to evidence (8), and general feedback (6). 
Support researchers, interest groups, educate people to understand why research/evidence can make a difference, online workshops, workshops at multisites PW4014

Teach the basics - it is not something as practitioners we are necessarily have experience with MW2032

[Name removed]'s comment about "If this was a group of emergency medicine clinicians..." Palliative care needs to move away from the "but we've always done it like this" and embrace outcome measures. DW5021

\section{Follow-Up Evaluation}

Thirteen follow up survey responses were received (table 4). It was hoped, but not assumed, that respondents were going to follow up on the workshop and plan changes in the workplace. Some were not in a position to do so the follow-up survey item was not applicable to them.

Respondents were also asked about barriers and facilitators to change in their workplace. Twelve respondents identified barriers. Time was highlighted as a key barrier but staff attitudes and lack of knowledge were also seen as issues.

Time, Lack of knowledge on how to change PW4013

Six responses proposed facilitators, which included staff engagement and patient care.

Promote staff interest and enthusiasm. Clearly defined activities with outlined goals. Targeted data collection MW2002 
Identification of issues that impact on patient care or staff workload. Fostering a team culture of continuing improvement. PW4013

\section{Discussion}

There is increasing interest in driving improvements to patient care and organisational efficiency, with many services needing to report on QI actions and initiatives. Many health professionals and palliative care services are taking on QI activities at the local level in response to needs that are being identified within the service or through data collection and self-assessment projects. However, those who are taking on these tasks within services are not necessarily being trained or supported in this work (Wilkinson et al 2011). Much of the research literature has focused on large scale interventions using particular methodologies which may have a limited applicability to local QI projects at the service level (Dilley, 2012).

Participation in, and evaluation of, the workshops suggests that the WTCF (and workshop methodology) were useful to individuals and services involved in QI activities. Participants appeared to recognise that successful QI interventions require skills and knowledge, and that they did not necessarily have the required competencies. The majority of the participants in the workshops were nurses, with many in more senior or advance practice roles, who would potentially have the expectation of initiating or leading QI activities in their organisation. The ages of the nurses in this research study correlate with current nursing workforce statistics (Australian Institute of Health and Welfare, 2013). As an older cohort (63.7\% were over the age of 50 ), many may not have been exposed to change management theories and methods in formal education and training, and may instead have been relying on experience and skills acquired in the workplace. It is only in more recent years that there has been an increasing focus on the importance of teaching evidence-based practice to nurses, that QI theories and models have been included in the curriculum and that evidencebased practice nursing competencies have been developed (Melnyk et al, 2014). However, 
it is worth noting that formal education does not necessarily ensure preparedness and capacity to undertake QI work (Kovner et al, 2010).

Nearly $90 \%$ of the participants reported that the content of the workshop was relevant to their needs. Several highlighted the benefit of having a framework that organised the work in discrete and manageable elements. For the majority of participants, and especially those with no formal training or little experience in QI, a framework consisting of a series of questions provides a roadmap to an end - point as well as specific directions to particular points along the way. The explicit relationship to evidence within the WTCF reminds users to consider existing research relevant to their improvement areas as well as evidence about effective strategies and approaches that can be used in planning, implementing and measuring their QI activity. Indeed, 81.8\% of those who completed workshop evaluations felt more confident in applying evidence-based solutions. Of those who completed the follow up survey, three quarters had discussed the role of evidence in change activities with service colleagues. Other emerging research is also highlighting the value of evidence reviews to support local QI initiatives (Danz et al, 2013).

Feedback about the value of the three projects working together highlights the benefit of cohesive and integrated networks and systems. Health professionals and services are time poor with competing demands and multiple areas of responsibility. By aligning the approach, services have the opportunity to draw upon resources and information from the three projects to guide their QI planning, decision making, implementation and monitoring activities. There is also the opportunity to extend QI activities such as collaborative workshops, to focus on common issues raised through self-assessment in NSAP and through clinical outcomes measurement. This remains a significant area for future work.

At the time of the follow - up evaluation, at 8 weeks, 7 of the 56 workshop participants (12.5\%) had identified a problem that they wanted to change. Several of these participants 
had already started identifying evidence to guide the QI activity and to assess its effectiveness. However, it is beyond the scope of this project to follow these participants to determine if the framework was successfully applied and supported QI activities.

Despite positive feedback on the WTCF and the workshops, it is unlikely that a single workshop, even with follow up emails, will provide the support that individual health professionals and health services need to solve the issues associated with implementing change. This project represents a single step in building awareness about the need for a structured and planned approach to QI and the role and contribution of evidence in QI processes. Responses from the participants highlighted the need for training and support in

QI activities and this remains a focus for the three projects. Some $76.8 \%$ of the workshop participants would recommend the workshop or an online equivalent to colleagues. However, the ability to implement ongoing or future workshops is also limited by cost and staff availability. The framework and associated resources could potentially be delivered online, formatted for specific groups, which would allow participants to complete it in their own time. Workshops via webinar could also be considered.

\section{Strengths and Limitations of Study Approach}

This study benefited from workshop participation from people involved in QI activities in services across Australia. Co-location of the WTCF workshop with a funded NSAP update meeting would have facilitated participation, particularly by attendees from rural and remote areas. The study also sought to promote the use of evidence in QI and to concentrate on QI processes rather focusing on than a specific QI content activity, such as introducing bereavement practices in palliative cares services.

Although a follow - up survey was undertaken, it did not directly address whether the service or individual had commenced a QI project. The response rate for the follow up study was relatively low at $23.2 \%$ suggesting that many workshop participants may not have 
undertaken any further work. The workshop format did not directly introduce the issue of management buy-in although this is already negotiated in both the NSAP and PCOC projects.

\section{Conclusion}

Recognising and addressing problems in clinical practice and service delivery is an important part of ensuring quality care for patients. Staff and services need support in developing the skills and knowledge that are essential to successful QI activities. The WTCF was developed to guide specialist palliative care services through a change cycle, and when it was delivered via workshops, services were able to see how it could work in practice.

The results of this evaluation will add to a growing body of knowledge on the difficulties health professionals face in using evidence to support their clinical practice and to carry out QI in the workplace. The evaluation also adds to considerations around the amount of support required for services to understand QI and its implementation and evaluation. The information gained by participants will in turn help to improve the direct care that is delivered within services and in the palliative care sector.

\section{Acknowledgments}

The workshops were conducted during 2012 with the following PCOC staff also contributing to their implementation: Tanya Pigeon, Jane Connolly, Carol Hope, Claire Kelly. We would like to acknowledge the work of Amanda Adams in managing the data collection and analysis.

CareSearch, PCOC and NSAP are funded by the Department of Health.

\section{Conflict of Interest}

The authors declare that there is no conflict of interest. 


\section{References}

Australian Institute of Health and Welfare (2013) Nursing and midwifery workforce 2012. National Health Workforce Series no. 6. Cat. no. HWL 52. Canberra: AlHW

Bosch M, Tavender E, Bragge P, Gruen R and Green S (2012) How to define 'best practice' for use in Knowledge Translation research: a practical, stepped and interactive process. Journal of Evaluation in Clinical Practice, 19(5):763-8

Cole MJ (2009) Benchmarking: a process for learning or simply raising the bar? Evaluation Journal of Australasia. 9(2):7-1

Clancy C, Margolis P and Miller M (2013) Collaborative networks for both improvement and research. Paediatrics. Suppl 4: S201-4

Dale J, Petrova M, Munday D, Koistinen-Harris J, Lall R and Thomas K (2009) National facilitation project to improve primary palliative care: impact of the Gold Standards Framework on process and self-ratings of quality. Quality and Safety in Health Care 18:174180

Danz M, Hempel S, Lim Y, Shanman R, Motala A, Stockdale S et al (2013) Incorporating evidence review into quality improvement : meeting the needs of innovators. British Medical Journal of Quality and Safety 22(11):931-9

Daugherty J, Blake S, Kohler S Culler S, Hawley J et al (2013) Quality Improvement training: experiences of frontline staff. International Journal of Health Care Quality Assurance 26(7):627-41

Dilley J (2012) Quality Improvement Interventions in Public Health Systems. American Journal of Preventative Medicine 42(5) Suppl 1:S58-S71 
Dy S, Aslakson R, Wilson R Fawole O, Lau B, Martinez K et al (2012) Closing the Quality gap: revisiting the state of the science (Vol 8: Improving health care and palliative care for advanced and serious illness) Evidence/ Report Technology Assessment (Full Rep) (208.8): 1-249.

Glasziou P, Ogrinc G and Goodman S (2011) Can evidence-based medicine and clinical quality improvement learn from each other? British Medical Journal of Quality and Safety. Apr;20 Suppl 1:i13-17

Gordon J, Leiman J, Deland E and Pardes H (2014) Delivering value: provider efforts to improve the quality and reduce the cost of health care. Annual Review of Medicine. Jan 14; 65:447-58.

Graneheim U, Lundman B. (2004) Qualiltatve concept analysis in nursing research: concepts, procedures and measures to achieve trustworthiness. Nurse Education Today 24:105-12

Haley M, Lettis A, Rose P, Jenkins L, Glasziou Pand Rose P (2012) Implementing evidence in practice: do action lists work? Education for Primary Care 23: 107-114)

Hughes R (Ed) (2008) Patient Safety and Quality: An Evidence-Based Handbook for Nurses. Rockville (MD): Agency for Healthcare Research and Quality (US) Apr. Vol, 3

Jones A, Williams A and Carson-Stevens A (2013) Integrating quality improvement into preregistration education. Nursing Standard 27, 29, 44-48. 
Kamal A, Bull J, Stinson C, Blue D, Smith R, Hooper, R et al (2011) Collecting data on quality is feasible in community-based palliative care. Journal of Pain and Symptom Management 42(5): 663-7

Kerridge J (2012) Leading Change: 1 - Identifying the issue Nursing Times 108 (4) 12-15

Kovner C, Brewer C, Yingrengreung S and Fairchild S (2010) New Nurses' Views of Quality Improvement Education. The Joint Commission Journal on Quality and Patient Safety 36 (1) :29-35

Lau B, Aslakson R, Wilson R, Fawole O, Apostol C, Martinez K et al (2013) Methods for improving the quality of palliative care delivery: A systematic review. American Journal of Hospice and Palliative Care Mar 26 [Epub ahead of print]

McDonald K, Schultz E and Chang C (2013) Evaluating the State of Quality-Improvement Science through Evidence Synthesis: Insights from the Closing the Quality Gap Series. The Permanente Journal. Fall;17(4):52-61

McMillan S, Small B and Haley W (2011) Improving hospice outcomes through systematic assessment: a clinical trial. Cancer Nursing 434(2):89-97

Melnyk B, Gallagher-Ford L, English Long L and Fineout-Overholt E (2014) The Establishment of Evidence-Based Practice Competencies for Practicing Registered Nurses and Advanced Practice Nurses in Real-World Clinical Settings: Proficiencies to Improve Healthcare Quality, Reliability, Patient Outcomes, and Costs. Worldviews on EvidenceBased Nursing,; 00:00, 1-11. 
Ovretveit J and Klazinga N (2012) Learning from large-scale quality improvement through comparisons. International Journal of Quality health care 24(5):463-9

Palliative Care Australia (2005) Standards for Providing Quality Palliative care for all Australians. May 2005

Smith J, Pearson L and Adams J (2013) Incorporating a service improvement project into an undergraduate nursing programme: A pilot study. International Journal of Nursing Practice. Nov 13. [Epub ahead of print]

Tieman J and Rawlings D (2008) Exploring Nurses Attitudes to, and Use of, an Online Palliative Care Resource. International Journal of Palliative Nursing 14(12); 587-594

van Bokhoven M, Kok G and van der Weijden T (2003) Designing a quality improvement intervention: a systematic approach. Quality and Safety in Health Care ;12:215-220

van Hoof T and Meehan T (2011) Integrating Essential Components of Quality Improvement into a New Paradigm for Continuing Education. Journal of Continuing Education in the Health Professions, 31(3):207-214

Wilkinson J, Powell A and Davies H (2011) Evidence: Are clinicians engaged in quality improvement? The Health Foundation, UK

Wong B, Levinson W and Shojania K (2012) Quality improvement in medical education: current state and future directions. Medical Education. Jan;46(1):107-19. 
Woo J, Cheng J, Lee J, Lo R, Hui E, Lum C et al (2011) Evaluation of a continuous quality improvement initiative for end of life care for older cancer patients. Journal of American Medical Directors Association 12(2): 105-13 
Figure 1: The Working Together Change Framework model as developed by the project team

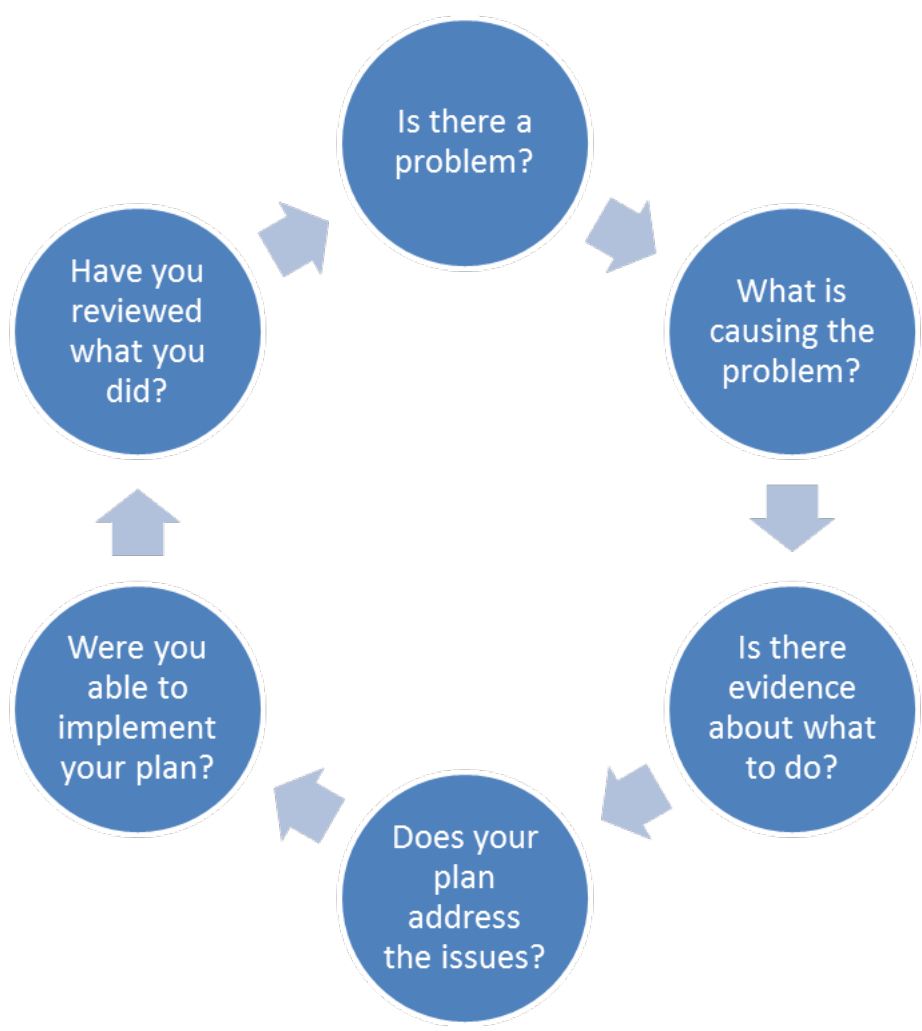


Figure 2: Overview of participation numbers

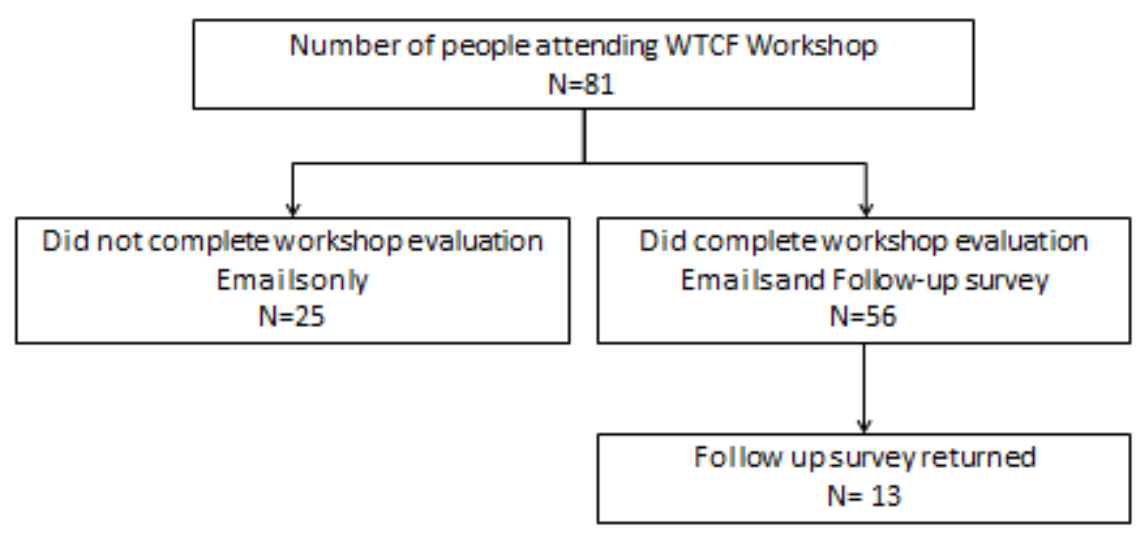


Table 1: Overview of workshop participant's role within the organisation

\begin{tabular}{|l|l|}
\hline Allied Health & 2 \\
\hline CEO & 1 \\
\hline Clinical Nurse Consultant & 3 \\
\hline Clinical Nurse specialist & 16 \\
\hline Consortia Manager & 1 \\
\hline Enrolled nurse & 1 \\
\hline Nurse educator & 0 \\
\hline Nurse Practitioner & 1 \\
\hline Nurse Unit Manager/ Associate & 7 \\
\hline Palliative Care Physician & 2 \\
\hline Palliative Care Registrar & 1 \\
\hline Project Nurse & 0 \\
\hline Quality Manager & 0 \\
\hline Regional Palliative Care Co-ordinator & 2 \\
\hline Registered nurse & 5 \\
\hline Researcher & 1 \\
\hline Research nurse & 3 \\
\hline Social Worker & 1 \\
\hline Volunteer Carer & \\
\hline Other & \\
\hline TOTAL & \\
\hline
\end{tabular}


Table 2: Age of workshop

participants

\begin{tabular}{|l|l|}
\hline $30-39$ yrs & $7.1 \%$ \\
\hline $40-49$ yrs & $28.6 \%$ \\
\hline $50-60$ yrs & $55.4 \%$ \\
\hline $60+$ yrs & $7.1 \%$ \\
\hline
\end{tabular}




\begin{tabular}{|c|c|c|c|c|c|}
\hline & $\begin{array}{l}\text { Strongly } \\
\text { agree }\end{array}$ & Agree & Not sure & Disagree & $\begin{array}{l}\text { Strongly } \\
\text { Disagree }\end{array}$ \\
\hline $\begin{array}{l}\text { The content of the workshop was } \\
\text { relevant to my needs }\end{array}$ & $\begin{array}{r}17 \\
(30.4 \%)\end{array}$ & $\begin{array}{r}33 \\
(58.9 \%)\end{array}$ & $\begin{array}{r}6 \\
(10.7 \%)\end{array}$ & $0(0 \%)$ & $0(0 \%)$ \\
\hline $\begin{array}{l}\text { After this workshop, I feel more } \\
\text { confident in analysing the cause } \\
\text { of problems that have been } \\
\text { identified in my service }\end{array}$ & $\begin{array}{r}6 \\
(10.9 \%)\end{array}$ & $\begin{array}{r}38 \\
(69.1 \%)\end{array}$ & $\begin{array}{r}9 \\
(16.4 \%)\end{array}$ & $2(3.6 \%)$ & $0(0 \%)$ \\
\hline $\begin{array}{l}\text { After this workshop, I feel more } \\
\text { confident in applying an evidence } \\
\text { based approach to addressing } \\
\text { these problems }\end{array}$ & $\begin{array}{r}7 \\
(12.7 \%)\end{array}$ & $\begin{array}{r}38 \\
(69.1 \%)\end{array}$ & $\begin{array}{r}8 \\
(14.5 \%)\end{array}$ & $2(3.6 \%)$ & $0(0 \%)$ \\
\hline $\begin{array}{l}\text { After this workshop I feel more } \\
\text { confident in looking at processes } \\
\text { involved in quality improvement }\end{array}$ & $\begin{array}{r}7 \\
(12.5 \%)\end{array}$ & $\begin{array}{r}36 \\
(64.3 \%)\end{array}$ & $\begin{array}{r}9 \\
(16.1 \%)\end{array}$ & $4(7.1 \%)$ & $0(0 \%)$ \\
\hline $\begin{array}{l}\text { After this workshop, I feel more } \\
\text { confident in implementing change } \\
\text { in my organisation }\end{array}$ & $4(7.3 \%)$ & $\begin{array}{r}35 \\
(63.6 \%)\end{array}$ & $\begin{array}{r}12 \\
(21.8 \%)\end{array}$ & $4(7.3 \%)$ & $0(0 \%)$ \\
\hline $\begin{array}{l}\text { After this workshop I feel more } \\
\text { confident in reassessing and } \\
\text { reviewing changes that have } \\
\text { been implemented }\end{array}$ & $2(3.6 \%)$ & $\begin{array}{r}42 \\
(76.4 \%)\end{array}$ & $\begin{array}{r}8 \\
(14.5 \%)\end{array}$ & $3(5.5 \%)$ & $0(0 \%)$ \\
\hline $\begin{array}{l}\text { After this workshop I feel more } \\
\text { confident in completing a PDSA } \\
\text { cycle as part of quality } \\
\text { improvement }\end{array}$ & $\begin{array}{r}7 \\
(13.2 \%)\end{array}$ & $\begin{array}{r}30 \\
(56.6 \%)\end{array}$ & $\begin{array}{r}13 \\
(24.5 \%)\end{array}$ & $3(5.7 \%)$ & $0(0 \%)$ \\
\hline
\end{tabular}




\begin{tabular}{|c|c|c|c|c|c|}
\hline $\begin{array}{l}\text { The use of NSAP and PCOC } \\
\text { scenarios and data made the } \\
\text { workshop more relevant }\end{array}$ & $\begin{array}{r}13 \\
(23.6 \%)\end{array}$ & $\begin{array}{r}38 \\
(69.1 \%)\end{array}$ & $3(5.5 \%)$ & $1(1.8 \%)$ & $0(0 \%)$ \\
\hline \multirow[t]{2}{*}{$\begin{array}{l}\text { I would recommend this } \\
\text { workshop (or its online } \\
\text { equivalent) to my colleagues }\end{array}$} & $\begin{array}{r}9 \\
(16.4 \%)\end{array}$ & $\begin{array}{r}34 \\
(61.8 \%)\end{array}$ & $\begin{array}{r}7 \\
(12.7 \%)\end{array}$ & $4(7.3 \%)$ & $1(1.8 \%)$ \\
\hline & $\begin{array}{l}\text { Extremel } \\
\text { y } \\
\text { satisfied }\end{array}$ & Satisfied & Not sure & $\begin{array}{l}\text { Dissatisfie } \\
\text { d }\end{array}$ & $\begin{array}{l}\text { Extremel } \\
y \\
\text { dissatisfi } \\
\text { ed }\end{array}$ \\
\hline Overall satisfaction & $\begin{array}{r}13 \\
(23.2 \%)\end{array}$ & $\begin{array}{r}30 \\
(53.6 \%)\end{array}$ & $\begin{array}{r}6 \\
(10.7 \%)\end{array}$ & $7(12.5 \%)$ & $0(0 \%)$ \\
\hline
\end{tabular}

NB: PDSA cycle: Plan Do Study Act 


\begin{tabular}{|c|c|c|c|}
\hline & Yes & No & Not \\
\hline $\begin{array}{l}\text { Since attending the workshop, have you } \\
\text { discussed the Working Together Change } \\
\text { framework with any of your colleagues? }\end{array}$ & $11(84.6 \%)$ & $2(15.4 \%)$ & \\
\hline $\begin{array}{l}\text { Since attending the workshop, have you } \\
\text { discussed the role of evidence in change } \\
\text { activities with your colleagues? }\end{array}$ & $10(76.9 \%)$ & $3(23.1 \%)$ & \\
\hline $\begin{array}{l}\text { Following the workshop, do you feel more } \\
\text { confident about undertaking QI and/or change } \\
\text { activities in your service? }\end{array}$ & $9(69.2 \%)$ & $4(30.8 \%)$ & \\
\hline $\begin{array}{l}\text { Since attending the workshops, have you } \\
\text { identified or thought of a problem that you want to } \\
\text { change? }\end{array}$ & 7 (53.9\%) & $6(46.1 \%)$ & \\
\hline $\begin{array}{l}\text { Since attending the workshop have you identified } \\
\text { any sources of evidence to support the need for a } \\
\text { change activity? }\end{array}$ & $6(46.1 \%)$ & 7 (53.9\%) & \\
\hline $\begin{array}{l}\text { Since the workshop have you thought of, or } \\
\text { developed, any appropriate strategies for } \\
\text { implementation of the changes you have } \\
\text { identified? }\end{array}$ & 6 (46.1\%) & $4(30.8 \%)$ & $3(23.1 \%)$ \\
\hline $\begin{array}{l}\text { Since the workshop, have you identified any } \\
\text { measures you could use to assess the success of } \\
\text { your change activity? }\end{array}$ & $4(40 \%)$ & $6(60 \%)$ & \\
\hline $\begin{array}{l}\text { Have you seen any problems in implementing } \\
\text { change within your workplace or organisation? }\end{array}$ & $9(69.2 \%)$ & $4(30.8 \%)$ & \\
\hline
\end{tabular}


